\title{
Interactive comment on "Impact of air pollution control measures and regional transport on carbonaceous aerosols in fine particulate matter in urban Beijing, China: Insights gained from long-term measurement” by Dongsheng Ji et al.
}

Dongsheng Ji et al.

jds@mail.iap.ac.cn

Received and published: 21 May 2019

Anonymous Referee \#3 Received and published: 12 March 2019

General comments The manuscript describe how EC and OC concentrations changed at Beijing between 2013 and 2017. Hourly EC/OC data is important and informative. However, interpretation of data is not equally robust. In some parts, discussions are very speculative. This is the main weakness of this paper. Seasonal, diurnal and inter- 
in $\mathrm{EC}$ and $\mathrm{OC}$ concentrations, using their own data is very informative, but the part where discussion of long-term variations are extended to 2002 using literature information is not that convincing. Authors applied nonparametric wind regression to locate local sources. This is a new tool and nicely applied in this work. They also applied PSCF to identify distant sources. I do not really think distant sources can be differentiated from local ones with PSCF, because every single trajectory ends up in Beijing, which is a huge source itself.

Response: We thank the reviewer for the constructive comments and suggestions. We have done our best to address all the comments and to improve our manuscript.

\section{SpeciïñĄc comments}

Comment 1 Figure 1. What is the "star" in the ïňAgure? Figure 1. Where is the ïñrst ring road? 4. Ring road? G6 highway? Please put these names on the map, so that reader can understand which roads you are referring to, or describe roads with notations on the map, such as, G108 etc.

Response: Thank you for pointing this out. The "star" denotes the study site. We have added the notations for the Third Ring Road, the Fourth Ring Road, the Fifth Ring Road, G6, G101, G102, G107, G108 and G109 in Fig. 1. The notations are provided near the roads and highways.

Comment 2 Lines 210 - 214. Authors discuss that concentrations of EC, OC and PM2.5 decreased from 2013 towards 2017. They should provide statistical signiïñ Acance of this comment. The difference between $14.0 \pm 11.7$ and $11.9 \pm 11.3$ (OC concentrations in 2013 and 2016, respectively) may or may not be statistically signiïñĄcant and must be tested. This comment also holds for EC and PM2.5 concentrations.

Response: Thank you for pointing this out. In Table 1, it can be seen that the annual average concentrations of both OC and EC peaked in 2014 and then started to decline gradually during the remainder of the study period. Nonetheless, the annual average 
concentration of PM2.5 was generally decreasing from 2013 to 2017 with a moderate peak in 2016. As advised by the reviewer, 2-tailed paired t-tests were applied for OC, EC and PM2.5 using their monthly average concentrations in 2013 and 2016 as paired datasets. At a confidence level of $98 \%$, from March to October, the paired data are statistically different, indicating that the concentrations of OC, EC and PM2.5 declined during the above period from 2013 to 2016; however, the concentrations of OC, EC and PM2.5 during November and February from 2013 to 2016 are not statistically different. This part has been modified in lines 219-232 in the revised manuscript.

Comment 3 For the same discussion. It will be better if authors should also present median concentrations of EC, OC and PM2.5 in table (maybe in parenthesis by the averages), which represent right-skewed data population better than average.

Response: Thank you for pointing this out. The median concentrations of EC, OC and PM2.5 have been added in Table 1 of the revised manuscript; as the median are lower than the averages, it can be concluded that the data populations for OC, EC and PM2.5 are right-skewed.

Comment 4 Line 230. "Compared to previous studies, the ratio of TC to PM2.5 became smaller ...." Last column in Table 1 suggests that TC-to-PM2.5 ratio did not change much between 2013 and 2018 in Beijing. Can the difference with "other" data be due to different characteristics of sampling locations, rather than time? Author's explanations with stringent measures make sense, but if that is the case shouldn't the TC/PM2.5 ratio decrease in ïñ Aqve years between 2013 and 2018 at their site as well?

Response: Thank you for pointing this out. The TC/PM2.5 ratio is not only associated with emission sources and different environment of the sampling locations, but also depends on the formation of secondary aerosols. Following up on the reviewer's comments and suggestion, we revised the relevant discussion in lines 249-263 in the revised manuscript: "Compared to previous studies in Beijing (Table S4), the TC to PM2.5 ratio became smaller, indicating a relatively lower contribution from carbona-

Printer-friendly version

Discussion paper 
ceous aerosols to PM2.5 in this study. The difference in the TC/PM2.5 ratio could be ascribed to two factors. One factor is the difference in characteristics of sampling locations between that in our study and those in the earlier studies. However, our site and those in the previous studies used for comparison are all located in urban areas of Beijing (Chaoyang and Haidian district, respectively). It is reasonable to assume that they are affected by common sources since the surrounding environments exhibit similar features. Besides, the annual average PM2.5 concentrations in both districts published by the Ministry of Environmental Protection of China (http://106.37.208.233:20035/) were quite comparable to each other from 2013 to 2017 ( $y=0.99 x, r 2=0.92$ ), indicating that both areas had particle pollution of a similar degree. The second factor is that the contribution from secondary inorganic aerosols to the PM2.5 became more important because of a stronger atmospheric oxidation capacity (the annual average $\mathrm{O} 3$ concentrations were 102, 109, 116, 119, and $136 \mu \mathrm{g} / \mathrm{m3}$, respectively, from 2013 to 2017 in the Beijing-Tianjin-Hebei region; published by http://106.37.208.233:20035/), which could give rise to a lower TC to PM2.5 ratio."

Comment 5 Line 237. Table you are referring to is Table 3 not Table 2.

Response: Our apologies for this error. We have corrected it.

Comment 6 Line 260 Authors should explanation the criteria they used to classify air quality as Excellent, good, LP, MP HP and SP

Response: Thank you for pointing this out. The criteria used to classify the air quality have been added in the revised manuscript. Air quality as Excellent, good, LP, MP, HP and SP were based on the daily average PM2.5 concentration, i.e., excellent $(0<\mathrm{PM} 2.5 \leq 35 \mu \mathrm{g} / \mathrm{m} 3)$, good (35<PM2.5 $\leq 75 \mu \mathrm{g} / \mathrm{m} 3$ ), lightly polluted (LP, $75<$ PM2.5 $\leq 115 \mu \mathrm{g} / \mathrm{m} 3$ ), moderately polluted (MP, $115<\mathrm{PM} 2.5 \leq 150 \mu \mathrm{g} / \mathrm{m} 3$ ), heavily polluted (HP, $150<\mathrm{PM} 2.5 \leq 250 \mu \mathrm{g} / \mathrm{m} 3$ ) and severely polluted (SP, PM2.5>250 $\mu \mathrm{g} / \mathrm{m3}$ ), respectively.

Comment 7 Line 271 - 305 Authors discussed long-term variation in concentrations of 
$\mathrm{EC}, \mathrm{OC}, \mathrm{SO} 2, \mathrm{NO} 2$ and tried to relate them with variations in fuel use and trafiñAc intensity. The discussion is very speculative. Particularly, attempts to link the drop in EC concentrations in 2010 (not in OC, not in SO2 and NO2) to moving a steel factory to somewhere else is not convincing.

Response: Thanks for the constructive comment. For better clarity, the last paragraph of section 3.2 has been modified in lines 345-353 in the revised manuscript: "Similar to $\mathrm{OC}$ and $\mathrm{EC}$, the annual mean $\mathrm{SO} 2$ and $\mathrm{NO} 2$ concentrations also showed a decreasing trend. As well-known, SO2 originates from coal combustion and sulfur-containing oil (Seinfeld and Pandis, 1998). With the replacement of coal for industrial facilities, residential heating and cooking by clean energy (e.g., natural gases, electricity and lower sulfur content in oil), a clear decline in annual SO2 concentrations was observed in the Beijing area starting from 2002. As compared to SO2, the annual decreasing rate of $\mathrm{NO} 2$ was relatively lower. Besides the power plants and other boilers, traffic emissions are another major source of NO2. The rapid increase of vehicle population may partly offset the great effort in reducing coal consumption to lower the NO2 level despite the transition to more stringent traffic emission standards."

Comment 8 More information should be provided about data they used from literature (2002-2012). Are these data from one study and from one measurement site, or are they from combination of various studies and various sites? This is important, because what you measure also depends on location of your sampling point. For example, can the drop they observed in EC concentrations in 2010 be an artifact due to different measurement point?

Response: Thank you for pointing this out. We have added the information for the data cited from literature (2002-2012, He et al., 2001; Zhao et al., 2013; Ji et al., 2016; Lang et al., 2017; Tao et al., 2017); information about the sampling sites is given in the references. A discussion on the decline in $\mathrm{OC}$ and $\mathrm{EC}$ concentrations has been added to substantiate its validity in lines 306-323 of the revised manuscript. Considering that measurements of OC and EC were rather scarce from 2002 to 2012, the comparison

Printer-friendly version

Discussion paper
Interactive

comment

\section{(1)}


of OC and EC between multiple sites cannot be used to exclude the difference caused by location of the sampling points. However, the annual average PM2.5 concentrations ACPD in the observation regions (Chaoyang and Haidian districts in Beijing) published by Ministry of Environmental protection, China (http://106.37.208.233:20035/) were very similar to each other from 2013 to 2017 ( $y=0.99 x, r 2=0.92)$.

References: He, K. B., Yang, F. M., Duan, F. K., Ma Y. L.: Atmospheric particulate matter and regional complex pollution, Science Press, Beijing, China. 310-327, 2011. Ji, D. S., Zhang, J. K., He, J., Wang, X. J., Pang, B., Liu, Z. R., Wang, L. L., and Wang, Y. S.: Characteristics of atmospheric organic and elemental carbon aerosols in urban Beijing, China, Atmos. Environ., 125, 293-306, 2016. Lang, J. L., Zhang, Y. Y., Zhou, Y., Cheng, S. Y., Chen, D. S., Guo, X. U., Chen, S., Li, X. X., Xing, X. F., Wang, H. Y.: Trends of PM2.5 and chemical composition in Beijing, 2000-2015. Aerosol Air Qual. Res., 17, 412-425, 2017. Tao, J., Zhang, L., Cao, J., and Zhang, R.: A review of current knowledge concerning PM2.âĂL'5 chemical composition, aerosol optical properties and their relationships across China, Atmos. Chem. Phys., 17, 94859518, https://doi.org/10.5194/acp-17-9485-2017, 2017. Zhao, P., Dong, F., and Yang, Y.: Characteristics of carbonaceous aerosol in the region of Beijing, Tianjin, and Hebei, China, Atmos. Environ., 71, 389-398, 2013.

Comment 9 Authors should also explain why only EC concentration dropped but not SO2 when a large steel industry stopped its operations in 2010.

Response: Thank you for pointing this out. As shown in Fig. 3, from 2010 to 2011, the concentrations of $\mathrm{OC}, \mathrm{EC}$ and $\mathrm{SO} 2$ have decreased. It is known that the clean air act was not started yet and the emission standards for most coal-intensive industries, including thermal power plants, had not been replaced yet by more stringent standards during that period. The significant decrease in coal consumption in 2011 compared to 2010 was to be ascribed to the relocation of Shougang Corporation and a few other highly polluting industrial facilities, which could lead to a decrease in OC, EC and SO2 levels. 
Comment 10 Line 315 Does "unfavorable meteorological conditions" mean lower mixing height, slower winds? Please state. (Unfavorable met conditions are later explained in the text. It will be better if they can bring that explanation here)

Response: Thank you for pointing this out. Unfavorable meteorological conditions included a lower mixing height and lower wind speeds (Ji et al., 2014), as indicated in line 365 in the revised manuscript.

Reference: Ji, D., Li, L., Wang, Y., Zhang, J., Cheng, M., Sun, Y., Liu, Z. R., Wang, L. L., Tang, G. Q., Hu, B., Chao, N., Wen, T. X., and Miao, H. Y.: The heaviest particulate air-pollution episodes occurred in northern China in January, 2013: Insights gained from observation, Atmos. Environ., 92, 546-556, 2014.

Comment 11 Lines 318 - 326 Authors observed decreasing EC and OC concentrations in "warm" months, but no similar decreasing trend in "cold" months. This is confusing, because throughout the manuscript they mentioned about more stringent measures of coal use, switching to cleaner forms of energy production etc. These all affect EC and $\mathrm{OC}$ concentrations in cold season, but hey observed decreasing pattern in warm season. Please explain. Please, also state in the text, how you deïnAzne cold and warm seasons.

Response: Thank you for pointing this out. For better clarity, the cold season extends from November to February next year when the centralized urban residential heating is provided, and the warm season starts in May and ends in October. In the warm season, lower OC and EC levels were observed, which could be attributed to the following factors: no extra energy consumed for domestic heating, strong wet scavenging by frequent precipitation occurring in these months, and more unstable atmospheric conditions favorable for pollutant dispersion; in addition, during this period, the monthly mean OC and EC concentrations generally decreased from year to year. In contrast, in the cold season, the monthly mean OC and EC concentrations did not show a clear decreasing trend from year to year except for October. In addition to the more intensive

Printer-friendly version

Discussion paper
Interactive

comment 
energy consumption in the cold season, the EC and OC levels could also be enhanced strongly by regional transport and stagnant meteorology, leading to ground surface accumulation in the autumn and winter (Wang et al., 2019; Yi et al., 2019); this would have counteracted the efficacy of the energy structure change in the Beijing-TianjinHebei region in the past few years. It is worth pointing out that, on a year to year basis, the monthly average OC and EC concentrations in the cold seasons of 2017 and 2018 were generally lower than those in 2016, demonstrating to some extent the effectiveness of the execution of the radical pollution control measures for cities on the air pollution in the Beijing-Tianjin-Hebei region. The modifications can be seen in lines 355-385 of the revised manuscript.

References: Wang, C., An, X., Zhang, P., Sun, Z., Cui, M., and Ma, L.: Comparing the impact of strong and weak East Asian winter monsoon on PM2.5 concentration in Beijing, Atmos. Res., 215, 165-177, 2019. Yi, K., Liu, J. F., Wang, X. J., Ma, J. M., Hu, J. Y., Wan, Y., Xu, J. Y., Yang H. Z., Liu, H. Z., Xiang, S. L., and Tao, S.: A combined Arctic-tropical climate pattern controlling the inter-annual climate variability of wintertime PM2.5 over the North China Plain. Environ. Pollut., 245, 607-615, 2019.

Comment 12 Line 323. What does "cyclic accumulation and scavenging process" mean?

Response: Thank you for pointing this out. The accumulation and scavenging processes occur in cycles because of changes in air mass origin and meteorological conditions. The concentration of particulate matter increases rapidly when the air mass back trajectories change from the northwest and north to the southwest and south over successive days in Beijing; in contrast, the concentration of particulate matter declines sharply when a cold front causes a shift of back trajectories from the southwest and south to the north and northwest (Ji et al., 2012). The accumulation processes are closely associated with unfavorable meteorological conditions, which give rise to higher $\mathrm{OC}$ and EC concentrations, while more scavenging of aerosols by cold fronts leads to lower levels. The modifications can be seen in lines 385-393 of the revised

Printer-friendly version

Discussion paper
Interactive

comment 
manuscript.

Reference: Ji, D. S., Wang, Y. S., Wang, L. L., Chen, L. F., Hu, B., Tang, G. Q., Xin, J. Y., Song, T., Wen, T. X., Sun, Y., Pan, Y. P., and Liu, Z. R.: Analysis of heavy pollution episodes in selected cities of northern China, Atmos. Environ., 50, 338-348, 2012.

Comment 13 Line 371 "The amplitude of the diurnal variation in the EC concentrations was smaller in the last three years." Please support this with trafïñ̨c counts.

Interactive

comment

Response: Thank you for pointing this out. It is a pity that no diurnal variations in traffic counts are available but the hourly average trafiňAc counts in 2015, 2016 and 2017 could be found in (Beijing Transportation Annual Report, http://www.bjtrc.org.cn/JGJS.aspx?id=5.2\&Menu=GZCG). The hourly average trafïňĄ counts in urban Beijing were 5969/hr, 5934/hr and 6049/hr in 2015, 2016 and 2017, respectively (Beijing Transportation Annual Report, http://www.bjtrc.org.cn/JGJS.aspx?id=5.2\&Menu=GZCG). Supposedly, the small amplitude of the diurnal variation in the last three years might be related to local emission intensities; these might been significantly affected by the enforcement of a series of traffic emission control measures since 2015, including more strict restriction of emission from heavy-duty diesel vehicle public buses, wider usage of electric public buses, and scrappage of all the high-emitting (yellow-labelled) vehicles, etc. (Table S2). All these actions led to a decline in emissions of $O C$ and EC and narrowed the amplitude of the diurnal variation in the EC concentration.

Comment 14 Line 393. "OC and EC exhibited higher concentrations on weekends than on weekdays" Statistical signiïñ Ącance of the difference between $13.2 \pm 1.8$ (OC in WE) and $11.8 \pm 1.8$ (OC in WD) and between $3.9 \pm 2.7$ (EC in WE) and $3.6 \pm 3.5$ (EC in WD) must be tested. These numbers are close to each other.

Printer-friendly version

Response: Thanks for the comment. The difference in $\mathrm{OC}$ and $\mathrm{EC}$ concentrations between weekends and weekdays was found to be statistically significant based on the analysis of the weekly data using t-test statistics. Hence, the above statement 
was modified in line 458 in the revised manuscript: OC and EC statistically $(p<0.05)$ exhibited higher concentrations on weekends than on weekdays in this study.

Comment 15 Also, please check the standard deviationsÂÿ given for OC in both WD and WE. They are too small to be real.

Response: Thanks for pointing this out. The standard deviations of OC in both WD and WE have been double checked and the correct average concentrations should be $13.2 \pm 11.8$ and $11.8 \pm 10.8 \mu \mathrm{g} / \mathrm{m} 3$ for $\mathrm{WD}$ and $\mathrm{WE}$, respectively. The related parts have been changed in lines 459 and 461 in the revised manuscript.

Comment 16 Line 434 "This could be because vehicular emissions became the dominant pollution source and gradually replaced the industrial emissions in Beijing". Handwaving. Must be removed.

Response: Thank you for pointing this out. This sentence is indeed very speculative and has been removed as suggested.

Comment 17 Line 489 ".... highlighting probable trans-boundary transport from highly industrialized regions upwind of the Hebei province of China ...", NWR is performed using surface meteorological data. How correct is it to infer long-distance transport with surface met data? Please explain in the text.

Response: Thank you for pointing this out. As the NWR analysis provides an allocation of local sources, we feel that it is inappropriate to infer the impact of long-range transport of air masses on the studied site. Hence, the trans-boundary transport inferred from the NWR results has been removed in the revised manuscript.

Comment 18 Line 493 "The joint probability data in Figs. 14 and 15 show...." There is only 10 ïňAgures in this paper.

Response: Our apologies for this error. We have modified them. All the joint probability data are shown in the right panels in Figs. 7 and 8. 
Comment 19 Line 500 "Considering that the NWR analysis can only provide an allocation of local sources, the PSCF analysis is a helpful complement to investigate potential advection of pollution over larger geographical scales" How realistic is it to attempt to locate distant sources using PSCF in the middle of a huge source like Beijing? No matter where they are coming from, all trajectories will end up in Beijing and will pick up pollutants emitted in Beijing. If every single trajectory is effected emissions in Beijing, it will be very difiñ Ącult (probably impossible) to differentiate information trajectories carry about distant sources. If you agree with me, please remove PSCF from manuscript. If you do not agree with me, please explain how you avoid this drawback in the text.

Response: Thanks for this comment, but we still believe that potential source contribution function (PSCF) is a useful tool to pinpoint non-nearby potential source areas, from which the air masses can affect the acceptor site via transboundary transport. It is extensively used in the literature for pinpointing non-nearby source areas; according to the Web of Science there are currently 465 publications in which "potential source contribution function" or PSCF was used. The detailed explanation of PSCF is as follows. PSCF is one type of residence time analysis of back trajectory endpoints within a fixed space, which provides the conditional probability that a given grid cell is within the source region of the pollutant species of interest if air mass trajectories passing through the cell give rise at the receptor site to measured levels of the pollutant above a pre-defined threshold value (Sofowote et al., 2011). Consequently, PSCF analysis is able to identify geographically-disperse source regions and the preferred pathways of contaminant species to a receptor site. In this study, we selected 48-h trajectories terminating at Beijing at a height of $100 \mathrm{~m}$ using the Trajstat software (Wang et al., 2009). 48-h trajectories with long pathways suggest that they have a rapid moving speed corresponding with relatively higher surface WS. When trajectories with long pathways are accompanied with a higher loading of the species of interest, it suggests that regional transport has an effect on the loading of species of interest at the receptor site. The PSCF calculations were performed on a longitude-latitude grid which covers the spatial 
domain of interest. We assume that a species emitted within a grid cell is swept into the air parcel and transported to the receptor site without loss through diffusion, chemical transformation or atmospheric scavenging. Let nij be the total number of trajectory segment endpoints falling in the grid cell (i, j) over the period of study, and let mij be the number of endpoints in (i, j) corresponding to trajectories associated with concentration values at the receptor site exceeding a specified threshold. The ratio, multiplied with a weighing factor, is then the conditional probability PSCF $(i, j)$ that an air parcel passing over the cell $(i, j)$ on its way to the receptor site arrives at the site with a concentration value above the threshold. Hence, high values in the spatial distribution of PSCF $(i, j)$ will pinpoint geographical regions that are likely to produce high concentration values at the receptor site. In order to identify the high PSCF values that might have arisen purely by chance, it is necessary to test these values against the null hypothesis that there is no association between concentrations and trajectories. The statistical significance of the spatial distribution of the PSCF values is examined by making use of a nonparametric bootstrap method. The method assumes that the concentration values are independent and identically distributed. We draw with replacement from the original concentration data set, $\mathrm{C}=\{\mathrm{c} 1, \mathrm{c} 2, \ldots, \mathrm{cN}\}, \mathrm{B}$ random subsamples of size equal to the length of the data set, $\mathrm{C}^{*}=\left\{\mathrm{c} 1^{*}, \mathrm{c} 2^{*}, \ldots, \mathrm{CN}^{*}\right\}$. We then calculate for each bootstrapped sample $k$ the corresponding PSCF spatial distribution, $W^{*} ; i j$. Let $W^{*} ; i j<\ldots<W(B)^{*} ; i j$ be the ordered values $\left\{\mathrm{Wk}^{*} ; \mathrm{ij}\right\} \mathrm{k}=1, \ldots, \mathrm{B}$, and let $\alpha$ be the chosen significance level. If $\left.\left\{\mathrm{Wk}^{*} ; \mathrm{ij}\right\} \geq \mathrm{W}^{*}(\mathrm{~B}+1)(1-\alpha / 2)\right) ; \mathrm{ij}$, the null hypothesis is rejected at the $(1-\alpha) \%$ confidence level. We decided to retain for our further analysis only the PSCF values satisfying the above relation. Note that if there is more than one trajectory assigned to a concentration value, the simple bootstrap on the concentration data set is equivalent to a blocked bootstrap on the trajectory set. In this study, a weighting function w(nij) was multiplied by the $\mathrm{mij} / \mathrm{nij}$ value when nij was lower than three times of the average number of trajectory endpoints (nmean) for each cell (Dimitriou and Kassomenos et al., 2015; Polissar et al., 2001). The weight function w(nij) is shown in the attachment as Fig.2.

The results of our PSCF analysis were consistent with the emission inventory data C12 
(Zhu et al., 2018), suggesting that our PSCF analysis is trustworthy.

\section{References:}

Dimitriou, K., and Kassomenos, P., 2015. Three year study of tropospheric ozone with back trajectories at a metropolitan and a medium scale urban area in Greece. Sci. Total Environ. 502, 493-501. Petit, J. E., Favez, O., Albinet, A., and Canonaco, F.: A user-friendly tool for comprehensive evaluation of the geographical origins of atmospheric pollution: Wind and trajectory analyses. Environ. Modell. Softw., 88, 183-187, 2017. Polissar, A.V., Hopke, P.K., Poirot, R.L.: Atmospheric aerosol over Vermont: chemical composition and sources. Environ. Sci. Technol. 35, 4604-4621, 2001. Sofowote, U. M., Hung, H., Rastogi, A. K., Westgate, J. N., Deluca, P. F., Su, Y. S., and McCarry, B. E.: Assessing the long-range transport of path to a sub-arctic site using positive matrix factorization and potential source contribution function. Atmos. Environ., 45(4), 967-976, 2011. Zhu, C., Tian, H., Hao, Y., Gao, J., Hao, J., Wang, Y., Hua, S., Wang, K., and Liu, H.: A high-resolution emission inventory of anthropogenic trace elements in Beijing-Tianjin-Hebei (BTH) region of China, Atmos. Environ., 191, 452-462, https://doi.org/10.1016/j.atmosenv.2018.08.035, 2018.

Interactive comment on Atmos. Chem. Phys. Discuss., https://doi.org/10.5194/acp-2019-42, 2019. 
ACPD

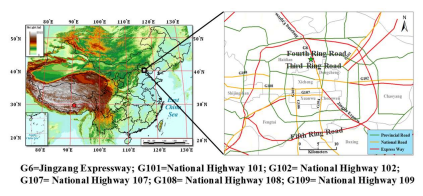

Interactive

comment

Fig. 1. 
ACPD

$w\left(n_{i j}\right)=\left\{\begin{array}{l}1.00,3 n_{\text {mean }}<n_{i j} \\ 0.70,1.5 n_{\text {mean }}<n_{i j} \leq 3 n_{\text {mean }} \\ 0.40, n_{\text {mean }}<n_{i j} \leq 1.5 n_{\text {mean }}\end{array}\right.$

Interactive

comment

Fig. 2.

Printer-friendly version

Discussion paper

C15

(c) (i) 